\title{
Impact of body mass index on long-term surgical outcomes of vascularized lymph node transfer in lymphedema patients
}

\author{
Pedro Ciudad ${ }^{1,2}$, Antonio J. Forte ${ }^{3}$, Maria T. Huayllani ${ }^{3}$, Daniel Boczar ${ }^{3}$, Oscar J. Manrique ${ }^{4}$, \\ Samyd S. Bustos ${ }^{4}$, Atenas Bustamante ${ }^{1}$, Hung-Chi Chen ${ }^{2}$ \\ ${ }^{1}$ Department of Plastic, Reconstructive and Burn Surgery, Arzobispo Loayza National Hospital, Lima, Peru; ${ }^{2}$ Department of Plastic and \\ Reconstructive Surgery, China Medical University Hospital, Taichung; ${ }^{3}$ Division of Plastic Surgery, and Robert D. and Patricia E. Kern Center \\ for the Science of Health Care Delivery, Mayo Clinic, Jacksonville, FL, USA; ${ }^{4}$ Department of Plastic and Reconstructive Surgery, Mayo Clinic, \\ Rochester, MN, USA \\ Contributions: (I) Conception and design: P Ciudad, AJ Forte, MT Huayllani; (II) Administrative support: AJ Forte, HC Chen; (III) Provision of study \\ materials or patients: P Ciudad, AJ Forte, HC Chen; (IV) Collection and assembly of data: P Ciudad, HC Chen; (V) Data analysis and interpretation: \\ AJ Forte, MT Huayllani, D Boczar; (VI) Manuscript writing: All authors; (VII) Final approval of manuscript: All authors. \\ Correspondence to: Hung-Chi Chen, MD, PhD, FACS. Department of Plastic and Reconstructive Surgery, China Medical University Hospital, 2 Yuh- \\ Der Road, 40447 Taichung. Email: D19722@mail.cmuh.org.tw.
}

Backgrounda Vascularized lymph node transfer (VLNT) is a surgical procedure with high interest to treat lymphedema. Body mass index (BMI) is a well-described factor that increases the risk of lymphedema, but little is known about its influence on the surgical outcomes of lymphedema patients who undergo VLNT. The aim of this study was to analyze the impact of preoperative BMI on the long-term surgical outcomes after VLNT in lymphedema patients.

Methods: We retrospectively compiled data of patients with International Society of Lymphology (ISL) stage II or III lymphedema who were treated with VLNT from July 2010 to July 2016 at China Medical University Hospital. Preoperative and postoperative demographic and clinical data, such as limb circumference and number of infection episodes were reviewed. Statistical analyses compared circumference reduction rates and infection episode reduction between preoperative BMI categories was done. In addition, prediction of outcomes based on quantitative preoperative BMI was analyzed.

Results: A total of 83 patients met the inclusion criteria. Nine patients $(10.8 \%)$ were normal weight, $43(51.8 \%)$ were overweight, and 31 (37.3\%) were obese. Compared with normal-weight patients, mean circumference reduction rates were significantly lower in overweight $(\mathrm{P}=0.005)$ and obese patients $(\mathrm{P}=0.02)$, but quantitative $\mathrm{BMI}$ was not correlated with circumference reduction rate $(\mathrm{P}=0.96)$. However, obese patients had a significantly greater reduction in infection episodes than normal-weight patients $(\mathrm{P}=0.03)$. In addition, greater BMI predicted greater reduction in infection episodes after VLNT $(\mathrm{P}=0.02)$.

Conclusions: VLNT is an effective surgical treatment, especially for lymphedema patients with higher preoperative BMIs. The results of our study suggest that this procedure considerably decreases the number of postoperative infection episodes per year in obese patients, even though preoperative BMI does not influence circumference reduction rate.

Keywords: Body mass index (BMI); obesity; lymph node transfer; surgical outcomes; lymphedema

Submitted Jan 27, 2020. Accepted for publication Feb 19, 2020.

doi: 10.21037 /gs.2020.03.13

View this article at: http://dx.doi.org/10.21037/gs.2020.03.13 


\section{Introduction}

Lymphedema is a chronic condition and is characterized by the accumulation of extracellular fluid after damage or dysfunction of the lymphatic system $(1,2)$. The first-line treatment for lymphedema patients is conservative therapy, but surgical therapies are considered if outcomes are not optimal. Our team have been studying the efficacy of multiple surgical procedures that may be used for treatment of lymphedema (2-16). Between them, vascularized lymph node transfer (VLNT) is a physiologic surgical therapy that consists of removing lymph node tissues from a donor site and transferring these free flaps to the lymphedematous limb $(4,17)$. The purpose of VLNT is to achieve normal limb size, reduce the number of infection episodes, and subsequently improve quality of life of these patients (18). This physiologic microsurgical treatment has shown promising results for lymphedema of the upper and lower limbs $(14,19,20)$.

Currently, studies have found a correlation between increased body mass index (BMI) and development of lymphedema (21-26). However, to date no studies have evaluated the impact of preoperative BMI on surgical outcomes, specifically those after VLNT in patients with lymphedema. In overweight or obese patients, excessive adipose tissue may predispose to greater lymphatic damage and consequently less lymphatic tissue that would make VLNT to be a promising option for patients with lymphatic ducts unsuitable for LVA. Hence, the aim of this study was to analyze the effect of preoperative BMI on circumference reduction rate and infection episode reduction and to determine whether BMI can predict surgical outcomes of lymphedema patients after VLNT.

\section{Methods}

We retrospectively searched for the records of all lymphedema patients treated with VLNT at China Medical University Hospital from July 2010 through July 2016. All patients had stage II or III lymphedema according to the 2016 criteria of the executive committee of the International Society of Lymphology (ISL). Only patients with 2 years of continuous follow-up were included. Patients with previous lymphedema surgical treatment were excluded from the study. VLNT was performed with groin, supraclavicular, gastroepiploic (open and laparoscopic approach), appendicular, and ileocecal lymph node flaps. The surgical techniques for each type of flap were described previously by Ciudad et al. (9,13,15,27-29).

We retrieved data about demographic characteristics, such as sex and age, and results of preoperative assessments, such as preoperative BMI, cause of lymphedema, duration of symptoms, location of lymphedema, and lymphedema stage. BMI was documented as a continuous variable, and patients were categorized as underweight $\left(<18.5 \mathrm{~kg} / \mathrm{m}^{2}\right)$, normal weight $\left(18.5-25 \mathrm{~kg} / \mathrm{m}^{2}\right)$, overweight $\left(25-30 \mathrm{~kg} / \mathrm{m}^{2}\right)$, and obese $\left(\geq 30 \mathrm{~kg} / \mathrm{m}^{2}\right)$.

The preoperative and postoperative circumferences of edematous and unaffected upper and lower limbs were measured to calculate the reduction rate. The postoperative measurement was documented at the last follow-up, before any other additional surgical procedure for lymphedema was performed. Circumference was measured at the following anatomical levels: $10 \mathrm{~cm}$ above the wrist or ankle, $10 \mathrm{~cm}$ below the elbow or knee, and at midhand or midfoot. The circumference reduction rate was defined as the percentage difference between the affected limb (AL) and the nonaffected limb (NAL), as determined with the following equation: circumference reduction rate $(\%)=[1-$ (postoperative $\mathrm{AL}-\mathrm{NAL}$ )/(preoperative $\mathrm{AL}-\mathrm{NAL}$ ) $\times 100$. No additional measurements performed after the second procedure were included in the equation.

Infection episode reduction per year was calculated by subtracting the number of postoperative infection episodes per year from the number of preoperative episodes.

Statistical analyses were performed to determine differences in mean circumference reduction rates and infection episode reduction among BMI categories. Oneway analysis of variance (ANOVA) was used to determine differences in mean values among BMI categories. Multiple linear regression was also used to evaluate correlations between BMI (as a continuous variable) and circumference reduction rate and infection episode reduction. This analysis also considered cause, location of lymphedema, ILS stage, and duration of lymphedema as possible predictive variables. The $\chi^{2}$ test was used to test for statistical differences in categorical variables among BMI categories, and one-way ANOVA was used to test continuous variables. We used SPSS software version 25 (SPSS Inc., USA) 
to perform the descriptive analysis. A $\mathrm{P}$ value $<0.05$ was considered significant.

\section{Results}

\section{Demographic data}

A total of 83 patients met the inclusion criteria and were included in the study (Table 1). The mean \pm SD age of our study population was $54.1 \pm 9.8$ years. Most patients were women $(78.3 \%)$, and the female to male ratio was 3.6 to 1 .

No patients were underweight, 9 (10.8\%) were normal weight, 43 (51.8\%) were overweight, and 31 $(37.3 \%)$ were obese (Table 1$)$. BMI ranged from 22.8 to $36.2 \mathrm{~kg} / \mathrm{m}^{2}$ for all patients. The mean $\mathrm{BMI} \pm \mathrm{SD}$ per category was $23.85 \pm 0.62 \mathrm{~kg} / \mathrm{m}^{2}$ for normal-weight patients, $27.31 \pm 1.20 \mathrm{~kg} / \mathrm{m}^{2}$ for overweight patients, and $31.50 \pm 1.82 \mathrm{~kg} / \mathrm{m}^{2}$ for obese patients. Mean follow-up \pm SD for all patients was $33.91 \pm 6.11$ months, without any statistical difference between $\mathrm{BMI}$ groups $(\mathrm{P}=0.9)$ (Table 1).

\section{Clinical information}

Regarding etiology of lymphedema, most patients [72 $(86.8 \%)]$ had secondary lymphedema, and only 11 patients (13.3\%) had primary lymphedema. A similar distribution was determined when patients were classified according to BMI category $(\mathrm{P}=0.84)$ (Figure 1$)$. The causes of secondary lymphedema included breast cancer (36.1\%), gynecologic cancer $(37.4 \%)$, urologic cancer $(3.6 \%)$, melanoma $(3.6 \%)$, and trauma $(6.0 \%)$.

All patients had unilateral lymphedema. Lymphedema was located in the upper limb in 30 patients $(36.1 \%$ ) and in the lower limb in $53(63.9 \%)$. The proportions of patients with lymphedema in each location were statistically different among BMI groups. Most overweight (62.8\%) and obese patients (77.4\%) had lower-limb lymphedema, whereas most normal-weight patients had upper-limb lymphedema $(77.8 \%, \mathrm{P}=0.01)$ (Figure 1$)$.

A total of 47 patients $(56.6 \%)$ had stage II lymphedema, and $36(43.4 \%)$ had stage III. When classified according to BMI category, similar proportions of overweight and obese patients had ISL stage II (48.8\% of overweight patients and $58.1 \%$ of obese patients) and stage III lymphedema $(51.2 \%$ of overweight patients and $41.9 \%$ of obese patients), but a higher proportion of normal-weight patients had stage II (88.9\%). However, these proportions were statistically similar among $\mathrm{BMI}$ groups $(\mathrm{P}=0.09)$ (Figure 1).

The mean preoperative duration of lymphedema symptoms was 47.81 [12-89] months. The mean length of hospital stay ranged from 6 to 15 days. BMI groups had statistically similar durations of symptoms $(\mathrm{P}=0.09)$ and lengths of hospital stay $(\mathrm{P}>0.99)$ (Table 1).

\section{Clinical outcomes}

\section{Circumference reduction rate}

Mean circumference reduction rates were statistically different among BMI groups $(\mathrm{F}[2,80]=5.68, \mathrm{P}=0.005)$ (Table 2). The mean circumference reduction rate of normal-weight patients was significantly higher than those of overweight $(\mathrm{P}=0.005)$ and obese patients $(\mathrm{P}=0.02)$ (Figure $2 A)$. Overweight and obese patients had similar rates $(\mathrm{P}=0.66)$ (Figure 2).

Multiple linear regression was calculated to predict circumference reduction rate on the basis of BMI, lymphedema etiology, location, stage, and duration of symptoms (Table 3). Location of lymphedema and ISL stage were significant predictors of circumference reduction rate $\left(\mathrm{F}[5,77]=9.30 ; \mathrm{P}<0.001 ; \mathrm{R}^{2}=0.38\right)$. The circumference reduction rate decreased by $5.48 \%$ among patients with lower-limb lymphedema $(\mathrm{P}=0.01)$ and decreased by $10.98 \%$ among patients with ISL stage III lymphedema $(\mathrm{P}<0.001)$. However, BMI was not a significant predictor of circumference reduction rate $(\mathrm{P}=0.96)$ (Figure $3 A)$.

\section{Infection episode reduction}

We also determined that mean reduction in number of infection episodes was significantly different among BMI groups $(\mathrm{F}[2,80]=6.46, \mathrm{P}=0.003)$ (Table 2). The mean reduction in infection episodes was significantly greater for obese patients than normal-weight patients $(\mathrm{P}=0.03)$ (Figure 2B). Normal-weight and overweight patients had similar reductions in infection episodes $(\mathrm{P}=0.20)$, as did overweight and obese patients $(\mathrm{P}=0.11)$ (Figure $2 B)$.

Multiple linear regression was also calculated to predict infection episode reduction per year on the basis of BMI, etiology, location, and stage of lymphedema and duration of symptoms (Table 3). Only BMI was a significant predictor of infection episode reduction $(\mathrm{F}[5,77]=2.74 ; \mathrm{P}=0.02$; $\left.\mathrm{R}^{2}=0.15\right)$. The infection episode reduction was increased by 0.10 per year for each increased $\mathrm{BMI}$ unit $(\mathrm{P}=0.03)$ (Table 3). No other variable was a significant predictor of 
Table 1 Demographics and clinical data of patients who underwent VLNT according to preoperative BMI categories

\begin{tabular}{|c|c|c|c|c|c|}
\hline Clinical characteristics & Normal, N=9 (10.8\%) & Overweight, $\mathrm{N}=43$ (51.8\%) & Obese, $\mathrm{N}=31(37.3 \%)$ & $P$ value* & Total, N=83 (100\%) \\
\hline Age & & & & 0.41 & \\
\hline Mean \pm SD & $54 \pm 8.57$ & $52.77 \pm 9.18$ & $55.87 \pm 10.92$ & & $54.06 \pm 9.80$ \\
\hline Sex, N (\%) & & & & 0.24 & \\
\hline Male & 0 & $10(23.26)$ & $8(25.81)$ & & $18(21.69)$ \\
\hline BMI, N (\%) & & & & $<0.001$ & \\
\hline Mean \pm SD & $23.85 \pm 0.62$ & $27.31 \pm 1.20$ & $31.50 \pm 1.82$ & & $28.5 \pm 2.92$ \\
\hline Range & $22.8-24.6$ & $25-29$ & $30-36.2$ & & $22.8-36.2$ \\
\hline Etiology, N (\%) & & & & 0.84 & \\
\hline Gynecological cancer & $1(11.11)$ & 15 (34.88) & $15(48.38)$ & & $31(37.35)$ \\
\hline Urological cancer & 0 & $1(2.33)$ & $2(6.45)$ & & $3(3.62)$ \\
\hline Melanoma & 0 & $2(4.65)$ & $1(3.23)$ & & $3(3.62)$ \\
\hline Traumatic & 0 & $4(9.30)$ & $1(3.23)$ & & $5(6.02)$ \\
\hline Location, N (\%) & & & & 0.01 & \\
\hline Upper limb & $7(77.78)$ & $16(37.21)$ & $7(22.58)$ & & $30(36.14)$ \\
\hline Lower limb & $2(22.22)$ & 27 (62.79) & $24(77.42)$ & & $53(63.86)$ \\
\hline Hospital stay (days) & & & & 1 & \\
\hline Mean \pm SD & $10.55 \pm 4.22$ & $10.51 \pm 4.67$ & $10.52 \pm 4.19$ & & $10.52 \pm 4.40$ \\
\hline Follow-up (months) & & & & 0.9 & \\
\hline Mean \pm SD & $34.77 \pm 4.44$ & $33.74 \pm 5.68$ & $33.90 \pm 7.18$ & & $33.91 \pm 6.11$ \\
\hline
\end{tabular}

*, Chi-square was performed to find significant differences between sex, etiology (primary and secondary), location, stage and BMI categories. One-way ANOVA evaluated significant differences between age, BMI, duration of symptoms, hospital stay, and follow-up means and BMI categories. SD, standard deviation; BMI, body mass index; VLNT, vascularized lymph node transfer; ANOVA, analysis of variance. 

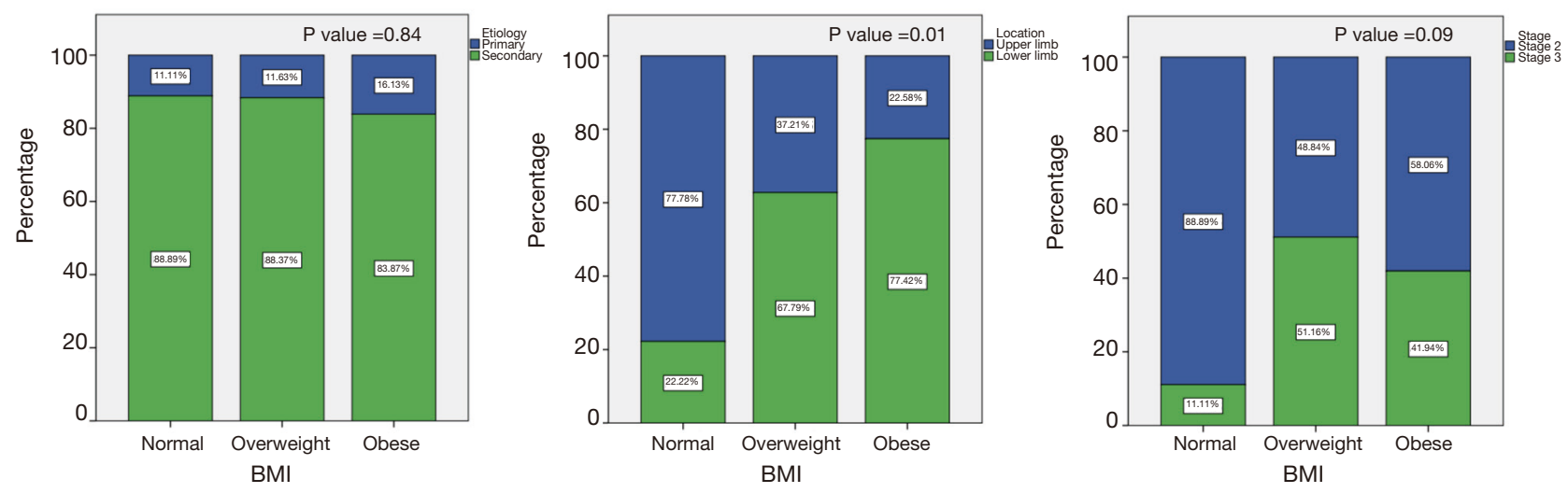

Figure 1 Comparison of etiology, location and stage rates between preoperative BMI categories. BMI, body mass index.

infection episode reduction (all P>0.05) (Figure 3B).

\section{Discussion}

Lymphedema is a long-term, incurable condition that affects quality of life (18). Symptoms and limb function may improve with different treatments, and of these, nonsurgical measures such as complete decongestive therapy are considered firstline interventions (30). However, when optimal results are not achieved or the patient's condition remains unchanged, surgical procedures are recommended (31).

LVA and VLNT use physiologic microsurgical methods to improve the lymphatic drainage (32). LVA has the potential to bypass areas with injured lymphatic vessels by redirecting lymph into the venous system, whereas VLNT improve the lymph drainage by transferring healthy lymph nodes (33-36). LVA is the preferred treatment of earlystage lymphedema before fibrosis develops, but it is a less effective treatment of more-advanced stages (35). VLNT has shown better results than LVA or conservative treatment of patients without available lymphatic vessels $(19,20)$. As a result, VLNT is being studied as a promising treatment for these cases.

Weight gain reportedly occurs in women after breast cancer treatment (37). A study showed that more than $60 \%$ of women treated for breast cancer had weight gain and more than $47 \%$ had weight gain of at least $5 \%$ (38). The pathophysiologic origin of weight gain after breast cancer may be associated with chemotherapy, but this association remains unclear (39).

Obesity is a major public health problem and has severe consequences for the arterial and venous microvasculature that may predispose patients to the development of lymphedema (40). High BMI is a well-described factor associated with the development of lymphedema (21-26). A prospective study evaluated 137 patients with breast cancer and reported that patients with a BMI greater than $30 \mathrm{~kg} / \mathrm{m}^{2}$ had 3 times the risk of having upper-limb lymphedema than patients with BMI less than $25 \mathrm{~kg} / \mathrm{m}^{2}$ (24). Another prospective clinical trial of 936 patients showed that patients with lymphedema had a higher baseline and current BMI than those without lymphedema (41). A long-term study that described the 5-year incidence of lymphedema also reported this association (42). A 5-year incidence of $36 \%$ was described for breast cancer patients with BMI greater than $29 \mathrm{~kg} / \mathrm{m}^{2}$, compared with $12 \%$ for patients with lower BMI (42). A meta-analysis also showed that obese patients were more likely to have lymphedema than overweight patients (43).

Most studies that have evaluated the relationship between higher BMI and lymphedema included patients with upperlimb lymphedema, but these findings can be extrapolated to patients with lower-limb lymphedema $(44,45)$. Greene et al. (46) reported significantly higher mean BMI in obese patients with lower-limb lymphedema than obese patients without lymphedema. The increased risk of lymphedema in obese patients has been ascribed to poor vascularity and extensive mastectomy operations with a high likelihood of lymphatic function disruption (42). In addition, in a heavier limb with more subcutaneous tissue, lymphatic fluid may accumulate in the adipose tissue and skin as a consequence of external compression of lymphatic vessels or direct inflammatory injury of the lymphatic endothelium $(24,44)$. Moreover, the lymphatic system may not have enough capacity to transport and drain fluid appropriately as the size of the obese limb and lymph production 
Table 2 Circumference reduction rate and infection episode reduction according to preoperative BMI categories

\begin{tabular}{|c|c|c|c|c|c|}
\hline Clinical outcomes & Normal $(\mathrm{N}=9)$ & Overweight $(\mathrm{N}=43)$ & Obese $(\mathrm{N}=31)$ & $P$ value* & Total \\
\hline Preoperative episodes of infection, mean \pm SD & $1.67 \pm 1.41$ & $3.35 \pm 1.02$ & $3.32 \pm 1.08$ & $<0.001$ & $3.16 \pm 1.19$ \\
\hline Postoperative episodes of infection, mean \pm SD & $0.44 \pm 0.72$ & $1.21 \pm 1.08$ & $0.68 \pm 0.75$ & 0.02 & $0.93 \pm 0.97$ \\
\hline Infection episode reduction, mean \pm SD & $1.22 \pm 1.30$ & $2.14 \pm 1.08$ & $2.64 \pm 0.98$ & 0.003 & $2.23 \pm 1.14$ \\
\hline
\end{tabular}

*, one-way ANOVA evaluated significant differences for circumference reduction rate, pre and postoperative episodes of infection and infection episode reduction means between BMI categories. SD, standard deviation; BMI, body mass index; ANOVA, analysis of variance.
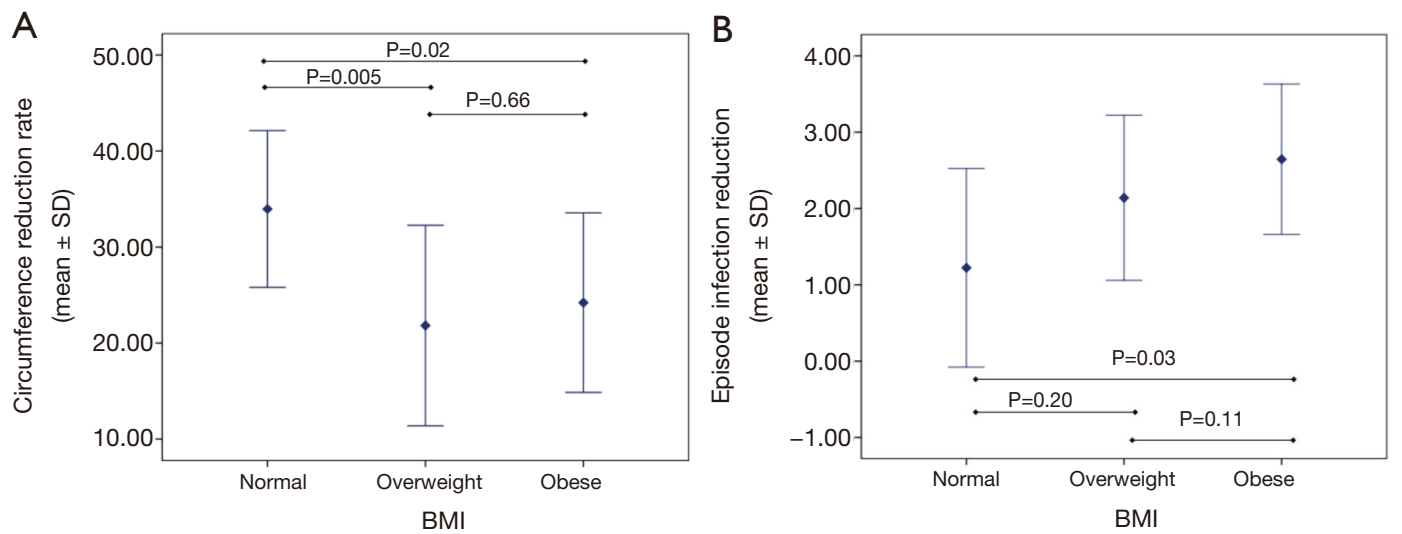

Figure 2 Comparison of circumference reduction rate and episode infection reduction means between preoperative BMI categories. (A) Circumference reduction rate (mean \pm SD) by BMI category; (B) episode infection reduction (mean \pm SD) by BMI category. SD, standard deviation; BMI, body mass index.

increase (47). Weitman et al. (48), in their experimental study, found that obese mice had smaller lymph node size, loss of follicular pattering of B cells and changes in lymph node inflammatory cell populations that may decrease the lymphatic transport capacity. However, little is known about how obesity affects the outcomes of surgical procedures for lymphedema. Shaw et al. (49) described improved outcomes in lymphedema patients who lost weight and were treated with compressive therapy. The volume of the affected arm was significantly reduced compared with that of the unaffected arm after 12 weeks of evaluation (49).

To our knowledge, this is the first single-center retrospective series to evaluate the impact of BMI on surgical outcomes after VLNT. We identified a greater circumference reduction rate in normal-weight patients than overweight and obese patients. This could be attributed to overweight patients having a lower likelihood of successful edema control than patients with a normal BMI (45). However, in our study, most overweight and obese patients had lower-extremity lymphedema, whereas most normal-weight patients had upper-extremity lymphedema. This might have influenced the circumference reduction rates. In our previous study, patients with upperlimb lymphedema had better outcomes than patients with lower-limb lymphedema, independent of BMI (8). This difference between patients with upper- versus lowerlimb lymphedema can be explained by increased adipose tissue deposition in the legs, closer proximity of lymphatic drainage from the upper limbs to the central venous circulation, and the smaller effect of gravity on lymph transport in the arms (47).

ISL stage was another predictor of circumference reduction rate. Patients with stage III lymphedema had lower circumference reduction rates than patients with stage II lymphedema $(\mathrm{P}<0.001)$. Late-stage lymphedema causes chronic interstitial fluid accumulation that leads to fibrosis, persistent inflammation, and adipose tissue deposition (44). The mechanism of how VLNT improves 

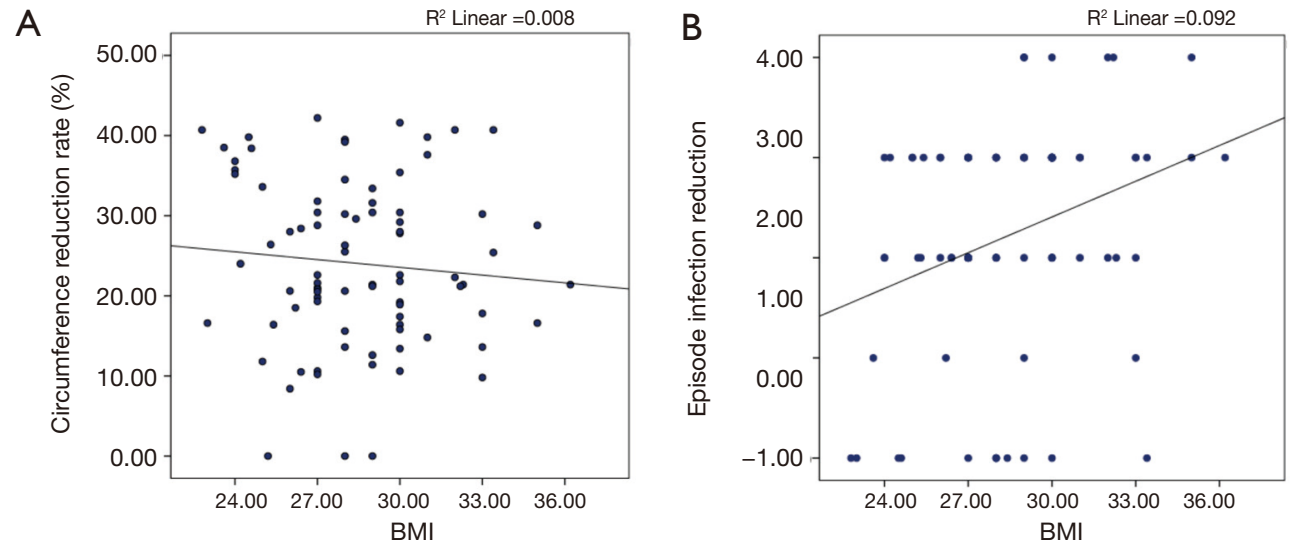

Figure 3 Correlation between preoperative BMI and circumference reduction rate or episode infection reduction. (A) Circumference reduction rate $v s$. quantitative preoperative $\mathrm{BMI}$; (B) episode infection reduction $v$ s. quantitative preoperative BMI. BMI, body mass index.

Table 3 Correlation between preoperative BMI and Circumference reduction rate and infection episode reduction

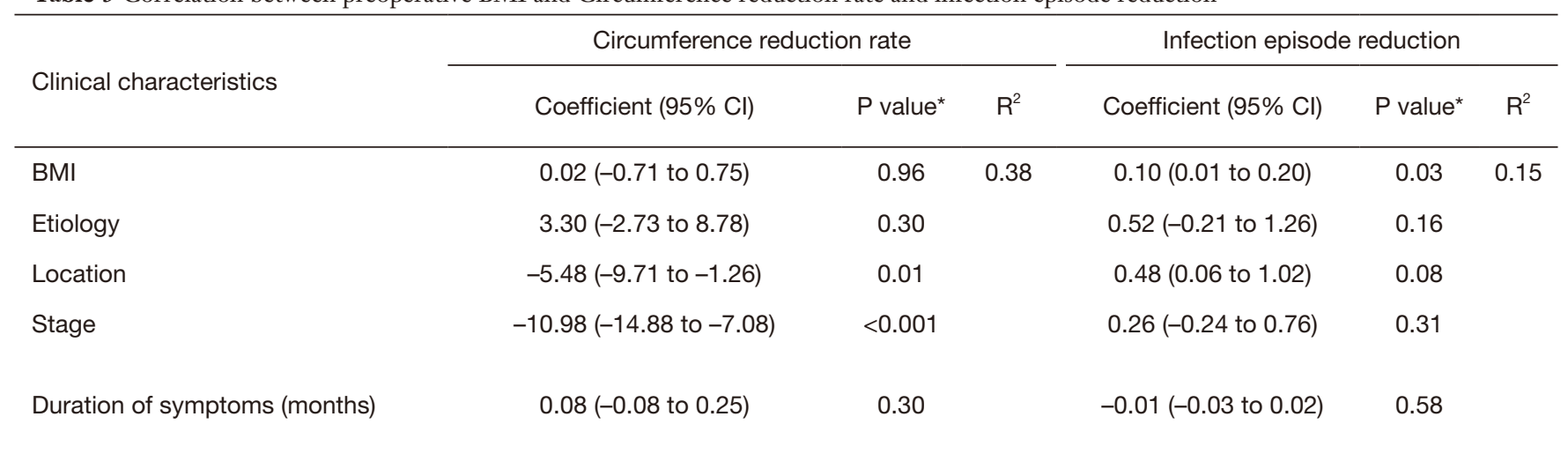

*, Multiple logistic regression evaluated significant correlation between numeric BMI and Circumference reduction rate and infection episode reduction adjusted by etiology, location, stage, and duration of symptoms. Cl, confidence interval; $\mathrm{R}^{2}$, $\mathrm{R}$ square; $\mathrm{BMI}$, body mass index.

lymphedema is still not well understood (20). A possible explanation is spontaneous neoformation of afferent and efferent lymphatic connections between the transferred lymph node and the recipient site; alternatively, the lymph node flap may act like a "vacuum" or "pump" to absorb and reroute lymphatic fluid into the venous system $(20,50)$. As a consequence, late-stage disease that presents with fibrosis prevents the actions of VLNT.

Interestingly, our study also showed that quantitative BMI could not be used to predict circumference reduction rate, even after we determined that the mean circumference reduction rates varied among patients in different BMI categories. Circumference measurement, as a volumetric measurement, is an inexpensive, safe, and painless method to assess lymphedema (51). However, it does not provide information about tissue composition of the limbs. Overweight and obese patients may have lower circumference reduction rates because of excessive adipose tissue in combination with fibrosis due to lymphedema rather than decreased postoperative volume. Noteworthily, patients with lymphedema have also observed to have an impairment of the clearance of lipids phagocytized by macrophages as a result of the physiological imbalance of blood flow and lymphatic drainage causing lipids deposition (52) that may have influenced in the circumference measurement rates.

On the other hand, differentiation of lymphedema of the lower extremities in overweight and obese patients from lipedema is important to acknowledge. Lipedema is a condition characterized by an atypical deposition 
of adipose tissue in the lower extremities that leads to increased circumferential of the extremity affected that ends at the ankles sparing the feet (53). In order to differentiate these two conditions, although the clinical characteristics of lymphedema to present involvement of feet and positive Stemmer's sign, evaluation of the lymphatic function with lymphoscintigraphy should be performed to confirmed diagnosis, as lipedema have a normal lymphatic function. In our study, all patients were clinically and lymphoscintigraphically confirmed to have lymphedema.

We also considered infection episode reduction per year as metric for evaluation of VLNT outcomes. Previous clinical studies have reported a decreased number of skin infections, such as erysipelas, lymphangitis, and cellulitis, in patients who underwent VLNT procedures for primary and secondary lymphedema $(10,33,34,54,55)$. Our current study shows that, compared with normal-weight patients, overweight and obese patients had significantly greater mean numbers of preoperative and postoperative infection episodes. Overweight and obese patients are more predisposed to skin infections and poor wound healing than normal-weight patients (56). In obese patients, the deep skin folds created by excessive skin serve as sites for bacterial colonization and stretch the skin, which result in microfissures that compromise the skin barrier and increase the risk of breakdown (57-59). Moreover, obese patients had a statistically greater mean reduction in the number of infection episodes than normal-weight patients. As a result, VLNT may be more suitable for obese patients because it may decrease the incidence of infections per year. Only BMI was a significant predictor of infection episode reduction. The reason for this finding still needs to be elucidated, but it may be attributable to the transfer of immune cells from lymph nodes during VLNT; this might decrease inflammation of obese skin at the recipient site in these patients.

Mehrara et al. (44)'s preliminary studies have shown that some of the changes caused by obesity on lymphatic function may be reversible due to calorie restriction in obese mice resulting in normalization of lymph node size and function. Therefore, the establishment of weight management programs including nutritional counseling and surgical weight loss options could produce a potential decrease in rates or severity of lymphedema (44). Assuring that patients comply with a weight-loss regimen would improve treatment outcomes, as previously suggested for programs that included this regimen (45). In addition, we believe that surgeons should consider BMI status when deciding the treatment approach for lymphedema patients, and this may help predict outcomes. That being said, we recommend that patients, specifically obese patients, control BMI preoperatively to decrease the incidence of infection after VLNT.

We acknowledge that this study has limitations. The retrospective design of this study has inherent biases related to data collection. Moreover, the sample population of this study may not be representative because we included patients from only one health care institution. However, we believe that this study is valuable because it is the first to report the impact of BMI on surgical outcomes after VLNT.

\section{Conclusions}

VLNT is a surgical technique that effectively benefit patients with lymphedema who present higher preoperative BMIs. We showed that obese patients with lymphedema had a significantly greater reduction in infection episodes per year than normal-weight patients. We also determined that preoperative BMI may be used to predict infection reduction rate after VLNT. However, preoperative BMI did not predict circumference reduction rate in lymphedema patients treated with VLNT, even after we showed that overweight and obese patients had lower mean circumference reduction rates than normal-weight patients. The results of this initial effort may be used in future multicenter studies with larger numbers of patients to better assess the impact of BMI on the surgical outcomes of VLNT for lymphedema.

\section{Acknowledgments}

Funding: This study was supported in part by Mayo Foundation for Medical Education and Research, by the Mayo Clinic Robert D. and Patricia E. Kern Center for the Science of Health Care Delivery, by the Mayo Clinic Center for Individualized Medicine, and by the Plastic Surgery Foundation.

\section{Footnote}

Provenance and Peer Review: This article was commissioned by the Guest Editors (Xiaona Lu, Antonio Jorge Forte) for the series "Lymphedema" published in Gland Surgery. The article was sent for external peer review organized by the Guest Editors and the editorial office. 
Conflicts of Interest: All authors have completed the ICMJE uniform disclosure form (available at http://dx.doi. org/10.21037/gs.2020.03.13). The series "Lymphedema" was commissioned by the editorial office without any funding or sponsorship. AJF served as the unpaid Guest Editor of the series. The other authors have no other conflicts of interest to declare.

Ethical Statement: The authors are accountable for all aspects of the work in ensuring that questions related to the accuracy or integrity of any part of the work are appropriately investigated and resolved. The study was approved by Institutional Review Board of China Medical University Hospital (DMR006-IRB-023) and informed consent was taken from all the patients.

Open Access Statement: This is an Open Access article distributed in accordance with the Creative Commons Attribution-NonCommercial-NoDerivs 4.0 International License (CC BY-NC-ND 4.0), which permits the noncommercial replication and distribution of the article with the strict proviso that no changes or edits are made and the original work is properly cited (including links to both the formal publication through the relevant DOI and the license). See: https://creativecommons.org/licenses/by-nc-nd/4.0/.

\section{References}

1. Rockson SG, Keeley V, Kilbreath S, et al. Cancerassociated secondary lymphoedema. Nat Rev Dis Primers 2019;5:22.

2. Ciudad P, Sabbagh MD, Agko M, et al. Surgical management of lower extremity lymphedema: a comprehensive review. Indian J Plast Surg 2019;52:81-92.

3. Forte AJ, Huayllani MT, Boczar D, et al. Lipoaspiration for the treatment of lower limb lymphedema: a comprehensive systematic review. Cureus 2019;11:e5913.

4. Forte AJ, Huayllani MT, Boczar D, et al. Lipoaspiration and lymph node transfer for treatment of breast cancerrelated lymphedema: a systematic review. Cureus 2019;11:e6096.

5. Forte AJ, Huayllani MT, Boczar D, et al. Lipoaspiration and controlled compressive therapy in lymphedema of the upper extremity: a comprehensive systematic review. Cureus 2019;11:e5787.

6. Forte AJ, Cinotto G, Boczar D, et al. Omental lymph node transfer for lymphedema patients: a systematic review. Cureus 2019;11:e6227.
7. Forte AJ, Boczar D, Huayllani MT, et al. Sympathetic nerve block in lymphedema treatment: a systematic review. Cureus. 2019;11:e5700.

8. Ciudad P, Manrique OJ, Bustos SS, et al. Comparisons in long-term clinical outcomes among patients with upper or lower extremity lymphedema treated with diverse vascularized lymph node transfer. Microsurgery 2020;40:130-6.

9. Ciudad P, Manrique OJ, Agko M, et al. Ileocecal vascularized lymph node transfer for the treatment of extremity lymphedema: a case report. Microsurgery 2019;39:81-4.

10. Ciudad P, Manrique OJ, Adabi K, et al. Combined double vascularized lymph node transfers and modified radical reduction with preservation of perforators for advanced stages of lymphedema. J Surg Oncol 2019;119:439-48.

11. Ciudad P, Agko M, Huang TCT, et al. Comprehensive multimodal surgical treatment of end-stage lower extremity lymphedema with toe management: The combined Charles,' Homan's, and vascularized lymph node transfer (CHAHOVA) procedures. J Surg Oncol 2019;119:430-8.

12. Ciudad P, Mouchammed A, Manrique OJ, et al. Comparison of long-term clinical outcomes among different vascularized lymph node transfers: 6-year experience of a single center's approach to the treatment of lymphedema. J Surg Oncol 2018;117:1346-7.

13. Ciudad P, Manrique OJ, Date S, et al. Vascularized appendicular lymph node transfer for treatment of extremity lymphedema: a case report. Microsurgery 2018;38:553-7.

14. Ciudad P, Maruccia M, Socas J, et al. The laparoscopic right gastroepiploic lymph node flap transfer for upper and lower limb lymphedema: technique and outcomes. Microsurgery 2017;37:197-205.

15. Ciudad P, Manrique OJ, Date S, et al. Double gastroepiploic vascularized lymph node tranfers to middle and distal limb for the treatment of lymphedema. Microsurgery 2017;37:771-9.

16. Maruccia M, Elia R, Ciudad P, et al. Postmastectomy upper limb lymphedema: Combined vascularized lymph node transfer and scar release with fat graft expedites surgical and patients' related outcomes. A retrospective comparative study. J Plast Reconstr Aesthet Surg 2019;72:892-901.

17. Suami H, Chang DW. Overview of surgical treatments for breast cancer-related lymphedema. Plast Reconstr Surg 2010;126:1853-63. 
18. Bernas M, Thiadens SRJ, Smoot B, et al. Lymphedema following cancer therapy: overview and options. Clin Exp Metastasis 2018;35:547-51.

19. Engel H, Lin CY, Huang JJ, et al. Outcomes of lymphedema microsurgery for breast cancer-related lymphedema with or without microvascular breast reconstruction. Ann Surg 2018;268:1076-83.

20. Pappalardo M, Patel K, Cheng MH. Vascularized lymph node transfer for treatment of extremity lymphedema: an overview of current controversies regarding donor sites, recipient sites and outcomes. J Surg Oncol 2018;117:1420-31.

21. Petrek JA, Senie RT, Peters M, et al. Lymphedema in a cohort of breast carcinoma survivors 20 years after diagnosis. Cancer 2001;92:1368-77.

22. Johansson K, Ohlsson K, Ingvar C, et al. Factors associated with the development of arm lymphedema following breast cancer treatment: a match pair case-control study. Lymphology 2002;35:59-71.

23. Clark B, Sitzia J, Harlow W. Incidence and risk of arm oedema following treatment for breast cancer: a three-year follow-up study. QJM 2005;98:343-8.

24. Helyer LK, Varnic M, Le LW, et al. Obesity is a risk factor for developing postoperative lymphedema in breast cancer patients. Breast J 2010;16:48-54.

25. Ridner SH, Dietrich MS, Stewart BR, et al. Body mass index and breast cancer treatment-related lymphedema. Support Care Cancer 2011;19:853-7.

26. Tsai RJ, Dennis LK, Lynch CF, et al. Lymphedema following breast cancer: the importance of surgical methods and obesity. Front Womens Health 2018. doi: 10.15761/FWH.1000144.

27. Ciudad P, Agko M, Perez Coca JJ, et al. Comparison of long-term clinical outcomes among different vascularized lymph node transfers: 6-year experience of a single center's approach to the treatment of lymphedema. J Surg Oncol 2017;116:671-82.

28. Ciudad P, Manrique OJ, Date S, et al. A head-to-head comparison among donor site morbidity after vascularized lymph node transfer: pearls and pitfalls of a 6-year single center experience. J Surg Oncol 2017;115:37-42.

29. Ciudad P, Orfaniotis G, Socas J, et al. Technical considerations to avoid microvascular complications during groin lymph node free flap transfer. Arch Plast Surg 2015;42:650-2.

30. Chang DW, Masia J, Garza R 3rd, et al. Lymphedema: surgical and medical therapy. Plast Reconstr Surg 2016;138:209S-18S.
31. Merchant SJ, Chen SL. Prevention and management of lymphedema after breast cancer treatment. Breast J 2015;21:276-84.

32. Carl HM, Walia G, Bello R, et al. Systematic review of the surgical treatment of extremity lymphedema. J Reconstr Microsurg 2017;33:412-25.

33. Lin CH, Ali R, Chen SC, et al. Vascularized groin lymph node transfer using the wrist as a recipient site for management of postmastectomy upper extremity lymphedema. Plast Reconstr Surg 2009;123:1265-75.

34. Cheng MH, Chen SC, Henry SL, et al. Vascularized groin lymph node flap transfer for postmastectomy upper limb lymphedema: flap anatomy, recipient sites, and outcomes. Plast Reconstr Surg 2013;131:1286-98.

35. Chang DW. Lymphaticovenular bypass for lymphedema management in breast cancer patients: a prospective study. Plast Reconstr Surg 2010;126:752-8.

36. Cheng MH, Huang JJ, Nguyen DH, et al. A novel approach to the treatment of lower extremity lymphedema by transferring a vascularized submental lymph node flap to the ankle. Gynecol Oncol 2012;126:93-8.

37. Makari-Judson G, Braun B, Jerry DJ, et al. Weight gain following breast cancer diagnosis: Implication and proposed mechanisms. World J Clin Oncol 2014;5:272-82.

38. Yaw YH, Kandiah M, Shariff ZM, et al. Pattern of weight changes in women with breast cancer. Asian Pac J Cancer Prev 2010;11:1535-40.

39. Wang JS, Cai H, Wang CY, et al. Body weight changes in breast cancer patients following adjuvant chemotherapy and contributing factors. Mol Clin Oncol 2014;2:105-10.

40. Hirt PA, Castillo DE, Yosipovitch G, et al. Skin changes in the obese patient. J Am Acad Dermatol 2019;81:1037-57.

41. McLaughlin SA, Wright MJ, Morris KT, et al. Prevalence of lymphedema in women with breast cancer 5 years after sentinel lymph node biopsy or axillary dissection: objective measurements. J Clin Oncol 2008;26:5213-9.

42. Werner RS, McCormick B, Petrek J, et al. Arm edema in conservatively managed breast cancer: obesity is a major predictive factor. Radiology 1991;180:177-84.

43. Wu R, Huang X, Dong X, et al. Obese patients have higher risk of breast cancer-related lymphedema than overweight patients after breast cancer: a meta-analysis. Ann Transl Med 2019;7:172.

44. Mehrara BJ, Greene AK. Lymphedema and obesity: is there a link? Plast Reconstr Surg 2014;134:154e-60e.

45. Stigant A. Tackling obesity as part of a lymphoedema management programme. Br J Community Nurs 2009;14:S9-12, 14. 
46. Greene AK, Grant FD, Slavin SA. Lower-extremity lymphedema and elevated body-mass index. N Engl J Med 2012;366:2136-7.

47. Greene AK, Maclellan RA. Obesity-induced upper extremity lymphedema. Plast Reconstr Surg Glob Open 2013;1:e59.

48. Weitman ES, Aschen SZ, Farias-Eisner G, et al. Obesity impairs lymphatic fluid transport and dendritic cell migration to lymph nodes. PLoS One 2013;8:e70703.

49. Shaw C, Mortimer P, Judd PA. A randomized controlled trial of weight reduction as a treatment for breast cancerrelated lymphedema. Cancer 2007;110:1868-74.

50. Saaristo AM, Niemi TS, Viitanen TP, et al. Microvascular breast reconstruction and lymph node transfer for postmastectomy lymphedema patients. Ann Surg 2012;255:468-73.

51. Gjorup C, Zerahn B, Hendel HW. Assessment of volume measurement of breast cancer-related lymphedema by three methods: circumference measurement, water displacement, and dual energy X-ray absorptiometry. Lymphat Res Biol 2010;8:111-9.

52. Brorson H. From lymph to fat: liposuction as a treatment for complete reduction of lymphedema. Int J Low Extrem Wounds 2012;11:10-9.

Cite this article as: Ciudad P, Forte AJ, Huayllani MT, Boczar D, Manrique OJ, Bustos SS, Bustamante A, Chen HC. Impact of body mass index on long-term surgical outcomes of vascularized lymph node transfer in lymphedema patients. Gland Surg 2020;9(2):603-613. doi: 10.21037/gs.2020.03.13
53. Peled AW, Slavin SA, Brorson H. Long-term outcome after surgical treatment of lipedema. Ann Plast Surg 2012;68:303-7.

54. Gharb BB, Rampazzo A, Spanio di Spilimbergo S, et al. Vascularized lymph node transfer based on the hilar perforators improves the outcome in upper limb lymphedema. Ann Plast Surg 2011;67:589-93.

55. Maldonado AA, Chen R, Chang DW. The use of supraclavicular free flap with vascularized lymph node transfer for treatment of lymphedema: a prospective study of 100 consecutive cases. J Surg Oncol 2017;115:68-71.

56. Yoon JA, Shin YB, Shin MJ, et al. An assessment of the relationship between abdominal obesity and the severity of upper extremity lymphedema. Lymphat Res Biol 2018;16:458-63.

57. Narayanarao T, Suvarchala A, Krishnababu G. Pseudosarcoma - massive localized lymphoedema in morbidly obese - a rare entity: Case report. Int J Surg Case Rep 2012;3:389-91.

58. García Hidalgo L. Dermatological complications of obesity. Am J Clin Dermatol 2002;3:497-506.

59. Ching DL, Anderson A, Kumarasinghe SP. Lower limb lymphoedema and obesity: a much-neglected association. Br J Hosp Med (Lond) 2015;76:542-3. 